\title{
Staged, hybrid approach to acute DeBakey Type I aortic dissection
}

\author{
Tim Smith, Robin H. Heijmen \\ Department of Cardiothoracic Surgery, St. Antonius Hospital, Nieuwegein, The Netherlands \\ Correspondence to: Robin H. Heijmen, MD, PhD. Department of Cardiothoracic Surgery, St. Antonius Hospital, Koekoekslaan 13234 CM, \\ Nieuwegein, The Netherlands. Email: r.heijmen@antoniusziekenhuis.nl.
}

Received: 08 March 2020; Accepted: 25 November 2020; Published: 20 April 2021.

doi: 10.21037/jovs-20-79

View this article at: http://dx.doi.org/10.21037/jovs-20-79

Defining the optimal surgical treatment for acute DeBakey type I aortic dissection remains challenging. Prompt surgery is indicated to prevent acute mortality due to cardiac tamponade, aortic valve insufficiency, or myocardial infarction due to coronary involvement. The classic principles of surgery for DeBakey type I dissection consist of (I) resection of the primary entry tear, (II) re-approximation of the dissected aortic wall layers [in our approach using the 'neomedia' technique using Teflon felt (1)], and (III) resuspension of the aortic valve. In case of an extensively dissected aortic root, presence of a pre-existent dilatation $(>45 \mathrm{~mm})$, known connective tissue disease, or unrepairable aortic valvulopathy, it is advised to also replace the aortic root lowering the risk of future proximal re-operations (2). Such an approach simplifies a complex problem, resulting in hemi-arch resection in the vast majority of patients (83\%, at our centre). In DeBakey type I patients, however, the downstream aorta usually remains residually dissected, risking late, distal aortic sequelae and, hence, leaving the patients at risk for future complex redo surgery. Whether a more extended distal repair at the index procedure (i.e., frozen elephant trunk) improves long-term outcome, and outweighs the associated surgical complexity and risks at the index procedure is currently being debated on (Video 1). Recent analysis of our institutional data using the aforementioned 'protocolized' approach (with the use of bilateral antegrade selective cerebral perfusion at 25 degrees Celsius core temperature) in $>250$ DeBakey type I aortic dissection patients in a 10-yrs period (2005-2015) demonstrated a $12 \% 30$-days mortality, $9 \%$ stroke rate, and $0.8 \%$ permanent spinal cord injury. Data that are in line with previously reported operative results in the IRAD Registry (3). At a mean follow-up of almost 70 months (99.6\% complete), we observed an acceptable survival-rate

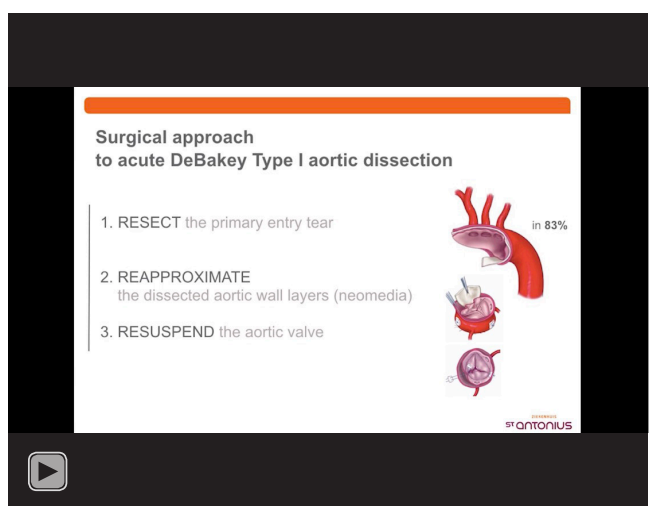

Video 1 Presentation elucidating on the concept of staged, hybrid treatment of DeBakey type I dissections.

of $86 \%$ at 5 -yrs, and $74 \%$ at 10 -yrs. Focusing on the need for redo surgery due to distal aortic sequelae, we observed a $13 \%$ overall reoperation rate (mainly post-dissection aneurysm). An additional $7 \%$ of patients in follow-up was considered too high risk for redo distal surgery of refused intervention. The magnitude of the downstream aortic problem is therefore larger than only the reported rate of redo distal surgery. As an alternative, we therefore focused on the late occurrence of post-dissection dilatation distally $(\geq 50 \mathrm{~mm})$. We observed a freedom of late dilatation of $81 \%$ at 5 -yrs, and $71 \%$ at 10 -yrs). So, roughly one in every 5 surviving patients dilated up to $50 \mathrm{~mm}$ or more in the downstream aorta. In parallelity to stent grafting in DeBakey type III aortic dissection, it is conceivable that immediate extended distal repair using the frozen elephant trunk technique may induce false lumen thrombosis and remodeling, thereby preventing late downstream dilatation. The aforementioned seems to occur, but comes with an increased risk of stroke, spinal cord injury, and above all 
increased surgical complexity, which is especially important considering the fact that these patients typically require emergent surgery in non-ideal timing, often performed by non-aortic surgeons. Since not all patients survive to late follow-up (30-days mortality of hemi-arch repair at our centre is $12 \%$ ), or have a residual dissection downstream after hemi-arch repair, a frozen elephant trunk strategy in all acute patients will put more patients at immediate risk (and costs) than that may benefit on the longer-term.

We, therefore, consider the frozen elephant trunk technique a too complex, risky, and costly procedure to be applied routinely to all our acute DeBakey type I patients (performed by all our (also non-aortic) surgeons). Nonetheless, we very much like the reported final result of such an extended repair, that excludes the false lumen at the upper thoracic aorta, which has the highest risk of late dilatation. Whether is really reduces the rate of late redo surgery distally is still studied. As an alternative approach to both the limited hemi-arch resection and the extended frozen elephant trunk technique, we favor a staged, hybrid approach. Already reported by Glauber and co-workers in 2011 (4). More recently Bavaria focused on this hybrid approach, which consists of a two-thirds aortic arch repair with separate branches to the brachiocephalic and left common carotid artery leaving a $3-\mathrm{cm}$ long Zone 2 landing zone, that enables future endovascular repair when considered necessary (5). Either by a singlebranched stented device, or simple stent grafting plus left subclavian artery revascularization. The proposed index procedure (stage 1, two-thirds branched arch repair) may be technically more feasible for a wider range of surgical arch expertise and, more importantly, may dismiss the patient from the risk of spinal cord ischemia at probably also a lower stroke rate, when compared to a frozen elephant trunk procedure in the acute setting.

Postoperatively, all patients are followed by regular CTscanning. Only in (younger) patients surviving the index procedure, with residual distal dissection and signs of early (false lumen) dilatation or predictors of poor outcome (cfr DeBakey type IIIb dissection), the second stage is offered consisting of simple stent grafting from Zone 2 to middescending aorta after LSA-revascularization, within 3 to 6 months after index repair to induce false lumen thrombosis and aortic remodeling (within the so-called 'window of plasticity'), and hence preventing late aneurysm formation, necessity for late redo distal surgery, and consequently improved late outcome.

Recently branched devices are being introduced and studied for total endovascular aortic arch repair. It is conceivable that in the (far) future a $3-\mathrm{cm}$ Zone 0 landing zone after 'simple' hemi-arch repair may suffice for staged, hybrid repair in DeBakey type I aortic dissection. Currently, however, we consider both the routine use of the complex frozen elephant trunk technique as single stage by the surgeon, as well as the complex total branched endovascular repair of the aortic arch by the interventionalist yet too complex, too risky, and too costly when compared to the staged, hybrid repair as described in this report.

\section{Conclusions}

In this manuscript we propose a staged, hybrid approach to DeBakey type I aortic dissection. The proposed procedure may be technically more feasible for a wider range of surgical arch expertise and, more importantly, may dismiss the patient from the risk of spinal cord ischemia at probably also a lower stroke rate, when compared to a frozen elephant trunk procedure in the acute setting.

\section{Acknowledgments}

Funding: None.

\section{Footnote}

Provenance and Peer Review: This article was commissioned by the Guest Editors (Roberto Di Bartolomeo, Davide Pacini, Mohamad Bashir) for the series "the 10th Postgraduate Course on 'Surgery of the Thoracic Aorta' in Bologna" published in fournal of Visualized Surgery. The article did not undergo external peer review.

Conflicts of Interest: Both authors have completed the ICMJE uniform disclosure form (available at https://jovs. amegroups.com/article/view/10.21037/jovs-20-79/coif). The series "the 10th Postgraduate Course on 'Surgery of the Thoracic Aorta' in Bologna" was commissioned by the editorial office without any funding or sponsorship. The authors have no other conflicts of interest to declare.

Ethical Statement: The authors are accountable for all aspects of the work in ensuring that questions related to the accuracy or integrity of any part of the work are appropriately investigated and resolved.

Open Access Statement: This is an Open Access article 
distributed in accordance with the Creative Commons Attribution-NonCommercial-NoDerivs 4.0 International License (CC BY-NC-ND 4.0), which permits the noncommercial replication and distribution of the article with the strict proviso that no changes or edits are made and the original work is properly cited (including links to both the formal publication through the relevant DOI and the license). See: https://creativecommons.org/licenses/by-nc-nd/4.0/.

\section{References}

1. Bavaria JE, Pochettino A, Brinster DR, et al. New paradigms and improved results for the surgical treatment of acute type A dissection. Ann Surg 2001;234:336-43.

2. Yang B, Norton EL, Hobbs R, et al. Short- and longterm outcomes of aortic root repair and replacement in

doi: $10.21037 /$ jovs-20-79

Cite this article as: Smith T, Heijmen RH. Staged, hybrid approach to acute DeBakey Type I aortic dissection. J Vis Surg 2021;7:22. patients undergoing acute type A aortic dissection repair: Twenty-year experience. J Thorac Cardiovasc Surg 2019;157:2125-36.

3. Parikh N, Trimarchi S, Gleason TG, et al. Changes in operative strategy for patients enrolled in the International Registry of Acute Aortic Dissection interventional cohort program. J Thorac Cardiovasc Surg 2017;153:S74-9.

4. Glauber M, Murzi M, Farneti P, et al. Aortic arch replacement with prophylactic aortic arch debranching during type A acute aortic dissection repair: initial experience with 23 patients. Eur J Cardiothorac Surg 2011;40:418-23.

5. Desai ND, Hoedt A, Wang G, et al. Simplifying aortic arch surgery: open zone 2 arch with single branched thoracic endovascular aortic repair completion. Ann Cardiothorac Surg 2018;7:351-6. 